\title{
Sarcoma sinovial del pie
}

\section{Sr. Director:}

Los sarcomas sinoviales representan un 5-10\% de los sarcomas de partes blandas. Su incidencia se estima en 2-3 casos por 100.000 habitantes/año. El $80 \%$ de los casos se diagnostican entre los 15 y los 40 años de edad ${ }^{1}$.

Más del $90 \%$ de los sarcomas sinoviales presentan una alteración citogenética característica que implica a los genes SSX, locus p11,2 del cromosoma $X$ y al gen SYT, locus q11,2 del cromosoma 18 , los cuales presentan una translocación y fusión ${ }^{2,3}$.

Los sarcomas sinoviales tiene predilección por las extremidades, sobre todo por las inferiores y concretamente en el pie, donde pueden confundirse con otros procesos, como bursitis, sinovitis o fascitis plantar ${ }^{4}$.

Por su rareza, nos parece interesante presentar brevemente un nuevo caso.

Se trata de un varón de 42 años en la actualidad, natural de Argentina, donde había residido hasta hace algunos meses.

Refería antecedentes personales de neumotórax espontáneo hacía 20 años, varices de extremidades inferiores, fumador de 15 cigarrillos al día.

Hace 2 años presentó dolor y tumefacción en el tobillo de la pierna izquierda, realizándose posteriormente una resonancia magnética nuclear, en la que se observó una formación nodular de aspecto heterogéneo, que medía unos 7 centímetros de diámetro, de localización medial al tendón de Aquiles, sin existir afectación ósea, predominantemente hipercaptante en T2 (Fig. 1).

El estudio de extensión realizado en que se incluyó una Tac toraco-abdominal fue normal, por lo que se realizó intervención quirúrgica, extirpándose una tumoración nodular de $8 \times 6 \times 5$ centímetros. El músculo estriado del lecho quirúrgico parecía estar afectado, lo que se confirmó en la anatomía patológica, el paquete vasculo-nervioso se encontraba indemne. Existían 5 mitosis por 10 campos, siendo el

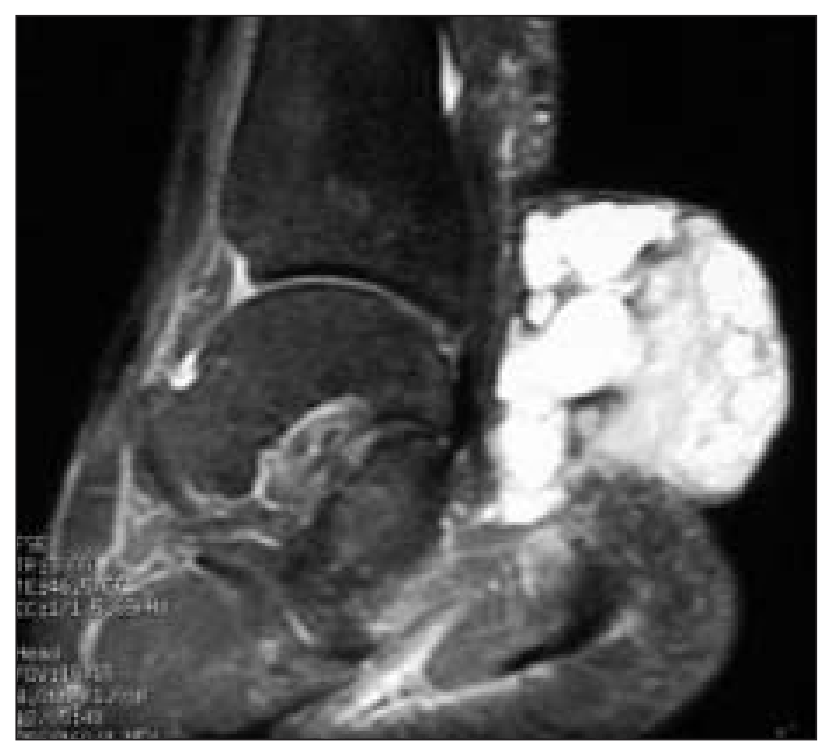

Figura 1.

grado histológico II. El estudio inmunohistoquímico fue positivo para vimentina y citoqueratina y negativo para S-100, actina, desmina, enolasa, HBM-45 y cromogranina; siendo compatible con sarcoma sinovial.

El estadio era pT2b N0 M0, estadio I.

La herida quirúrgica mostró una evolución tórpida, lo que impidió la realización de radioterapia adyuvante.

Repetidas biopsias de la zona intervenida mostraron tejido de granulación, sin evidenciar células malignas. Los estudios de imagen efectuados periódicamente, tanto en su país como en nuestro centro y que incluían RNM de la zona intervenida, radiografías de tórax y Tac toraco-abdominal, fueron normales sin evidenciar datos de recidiva.

Las manifestaciones clínicas más frecuentes del sarcoma sinovial, son el dolor, habitualmente poco intenso y la tumefacción local, con la aparición de una masa yuxtaarticular, sin afectación vascular, adenopatías regionales o síntomas sistémicos, lo 
cuál favorece el retraso diagnóstico, presentando en ocasiones demoras diagnósticas superiores a un año ${ }^{4}$.

En la mitad de los casos las radiografías simples se interpretan como normales, en el 30\% existen calcificaciones irregulares, habitualmente localizadas en la periferia y en menos del $20 \%$ de los casos existen signos de invasión del tejido óseo ${ }^{1}$.

La TAC y la RNM son las técnicas de imagen que proporcionan mayor información, mostraran una masa de tejidos blandos, calcificación e invasión del hueso y en la RNM se observará un tumor heterogéneo, con septos de intensidad intermediabaja que infiltra los márgenes ${ }^{5}$.

El diagnóstico diferencial radiológico debe realizarse con las siguientes entidades: calcinosis tumoral, osteosarcoma, fibrosarcoma de tejidos blandos o fibrohistiocitoma maligno, condrosarcoma de tejidos blandos, gota, miositis osificante, condroma de tejidos blandos, sinovitis vellonodular, liposarcoma, hemangioma y hemangiosarcoma.

El tratamiento de los sarcomas sinoviales se basa en la combinación de cirugía radical y radioterapia. Hay que efectuar una resección amplia con márgenes de seguridad de al menos 5 centímetros, siendo en ocasiones necesaria la realización de amputaciones.

La quimioterapia se emplea cuando no es posible realizar la resección completa de la tumoración o en los casos en que existen metástasis, aunque también puede emplearse cuando existen factores de mal pronóstico, como son el tamaño superior a 5 centímetros, elevada actividad mitótica, invasión vascular y escasa diferenciación celular ${ }^{6,7}$.

Casi la tercera parte de los sarcomas sinoviales presentan recurrencias locales ${ }^{7}$ y el $10 \%$ de los pacientes fallecen en el curso del primer año tras el diagnóstico a causa de las metástasis, sobre todo las pulmonares $^{8}$.

A los cinco años la supervivencia media es del $50-60 \%$.

\section{Bibliografía}

1. Enzinger FM, Weiss SW. Synovial sarcoma. En Soft tissue tumors. $3^{a}$ ed. St. Louis: Mosby-Year book. 1995; 757-786.

2. Kawai A, Woodruff J, Healey JH, Brennan MF, Antonescu CR, Ladanyi M. SYT-SSX fusion as a determinant of morphology and prognosis in synovial sarcoma. N Engl J Med 1998; 338: 153-160.

3. Coindre JM, Pelmus M, Hostein I, Lussan C, Bui BN, Guillou L. Should molecular testing be required for diagnosis synovial sarcoma ? Cancer 2003; 98: 2700-2707.

4. Scully SP, Temple HT, Harrelson JM. Synovial sarcoma of the foot and ankle. Clin Orthop 1992; 364: 220-226.

5. Jones BC, Sundaram M, Kransdorf MJ. Synovial sarcoma: MR imaging findings in 34 patients. AJR 1993; 161: 827830.

6. Ferrari A, Gronchi A, Casanova M, Meazza C, Gandola L, Collini P, et al. Synovial sarcoma: a retrospective analysis of 271 patients of all ages treated al a single institution. Cancer 2004; 101: 627-637.

7. Bergh P, Meis-Kindblom JM, Gherlinzoni f, Berlin O, Bachini P, Bertoni F, et al. Synovial sarcoma. Identification of low and high risk groups. Cancer 1999; 85: 2596-2607.

8. Skytting B, Meis-Kindbloom JM, Larsson O, Virolainen M, Perfekt R, Akerman M, et al. Synovial sarcoma. Identification of favourable and unfavourable histologic types. A Scandinavian Sarcoma Group Study of 104 cases. Acta Orthop Scand 1999; 70: 543-554.

9. Gómez Rodríguez N, Pintado García A, Ibáñez Ruán J, González Pérez M. Varón de 63 años con dolor y tumefacción retrocalcánea derecha. Reum Clin 2006; 2: 107-109.

F. Marcos Sánchez, F. Juárez Ucelay, $M^{a}$ I. Albo Castaño, A. Viana Alonso, J. Gómez Martín, A. Moyano Jato Servicio de Medicina Interna-Oncología Médica Hospital N ${ }^{a} S^{a}$ del Prado de Talavera de la Reina

Toledo

Correspondencia:

Dr. F. Marcos Sánchez

C/ Gregorio Corrochano, 1

E-45600 Talavera de la Reina (Toledo) 